\title{
Editorial
}

\section{Forecasting forward}

Journal of Revenue and Pricing Management (2014) 13, 411-412. doi:10.1057/rpm.2014.33

Forecasting is untangling the future and Revenue Management is part of the process of prediction. In this issue, we delve into some of the mysteries of the science. Fiig and colleagues present a forecasting methodology that enables forecasting in general fare structures (or, equivalently, demand models), including restricted, semi-restricted, unrestricted and fare families. The contribution is focused on two areas: first, the establishment of a measurement of forecast, and second a parametric forecast model for a general demand model. During the early part of this century the introduction of simplified fare structures led to serious revenue loss (so-called 'spiral down') that rendered traditional Revenue Management Systems useless. What this article addresses very well is re-establishing the measurement of forecast accuracy to be applicable to dependent demand models by introducing a constrained forecast accuracy measure.

Azadeh and colleagues ponder how Revenue Management Systems rely on customer data, and are thus affected by the absence of registered demand that arises when a product is no longer available, and review the uncensoring (or unconstraining) techniques that have been proposed to deal with this issue. Demand forecasting may well be the most critical area in Revenue Management, and demand unconstraining clearly lies at the heart of the matter. The selection of a flawed demand model can have an adverse effect from the point of view of Revenue Management, through bad pricing and inventory management decisions. In the airline industry, seat availabilities for high-fare classes that are based on uncensored historical data may underestimate the required protection levels and yield suboptimal revenues or, worse, dynamically induce a downward spiral in both high-fare protection levels and revenue, thus stressing that the choice of an uncensoring method is context dependent. The authors provide a comprehensive overview of this topic through a taxonomy classification.

Yang and colleagues delve into the rapid growth of online games, and firms that increasingly sell virtual goods for use within their online game environments. Determining prices for such virtual goods is inherently challenging due to the absence of an explicit supply curve as the marginal cost of producing additional virtual goods is negligible. New product releases have an impact on revenue using Auto Regressive Integrated Moving Average with intervention analysis. The authors show that in the initial days after a new product release, the firm's daily revenue increases significantly.

Pekgun and colleagues apply Revenue Management to golf, considering the common characteristics of these traditional industries with fixed and perishable capacity. Revenue Management practices have started to extend to new frontiers, one of which is the golf industry. For a golf course manager, while the primary focus may be on improving profitability by increasing golf course utilization, there is also a great potential to further improve profitability through Revenue Management by increasing the revenue derived from each tee-time. As a key performance indicator of Revenue Management, hotels measure their revenue per available room night and airlines measure their 
revenue per available seat mile. Similarly, golf courses would measure their revenue per available tee-time. The issue is a process of risk as the challenge is that the cost of overbooking may be difficult to measure. If overbooking is applied to earlier time-bands during the day, and more customers show up than anticipated, some customers may have to wait longer to start their first round of golf. However, all booked players can still be accommodated if no-shows do occur at some point during the day. On the other hand, if overbooking is applied to late timebands, then the impact may well be that some booked players are not able to complete their games, which is more difficult to measure. Zatta and Kolisch apply Revenue Management to the process industry, stating that the greater the turnover and the level of internationalization, the more likely a company is to use Revenue Management. They observe that both the a priori estimation of profit improvement due to Revenue Management before its introduction and the a posteriori realized profit improvement due to Revenue Management are positive. The profit improvement due to Revenue Management is increasing with the period of use and differs between Europe and North America, being higher in the latter. The final paper in the issue, by Yeoman, ponders the role of gamification of price in Revenue Management. As an endnote, Mauri's new book Hotel Revenue Management: Principles and Practices is reviewed.

Ian Yeoman

Editor

E-mail: ian.yeoman@vuw.ac.nz 